\title{
Postgastrectomy follow-up in the West: evidence base, guidelines, and daily practice
}

\author{
Magnus Nilsson ${ }^{1,2}$
}

Received: 30 August 2016/Accepted: 28 September 2016/Published online: 7 October 2016

(C) The Author(s) 2016. This article is published with open access at Springerlink.com

\begin{abstract}
Follow-up after gastrectomy for gastric cancer has several purposes, including management of side effects of surgery, oncological recurrence surveillance, psychological support, and data collection for research. How follow-up after gastrectomy, and especially recurrence surveillance, is performed differs immensely between different Western countries, despite guidelines from Western oncological organizations quite unanimously advocating symptom-driven surveillance, without scheduled cross-sectional imaging, endoscopies, or analysis of tumor markers. Given a complete lack of randomized data, the available body of observational data does not support intensive routine surveillance for recurrent disease. Moreover, studies of other cancers have shown a negative emotional impact of routine surveillance. There is an apparent need for randomized controlled trials to address the issue of optimized strategies for postgastrectomy recurrence surveillance.
\end{abstract}

Keywords Follow-up · Gastric cancer · Gastrectomy · Recurrence surveillance

\section{Introduction}

In recent years a number of pivotal randomized controlled trials covering different aspects of gastric cancer management have been performed [1-6], substantially improving

Magnus Nilsson

magnus.nilsson@ki.se

1 Division of Surgery, Department of Clinical Science, Intervention and Technology, Karolinska Institutet, Karolinska University Hospital, Kirurggatan 53, 14186 Stockholm, Sweden

2 Center for Digestive Diseases, Karolinska University Hospital, Kirurggatan 53, 14186 Stockholm, Sweden the evidence platform on which treatment decisions are made and paving the way for increased standardization of stage-specific management. Despite these advances, there is no international consensus on the best strategy for follow-up after curatively intended gastrectomy for gastric cancer. A recent publication showed that even within the relatively homogeneous group of countries in western and central Europe, national guidelines and practice differ immensely regarding postgastrectomy recurrence surveillance [7].

Follow-up after gastrectomy for gastric cancer has several components that meet different objectives. The first and most immediate reason to follow up patients after gastrectomy is the management of side effects caused by surgery, many of which are associated with eating and nutrition, including malabsorption, weight loss, and subjective alimentary discomfort [8]. Another obvious objective of follow-up after gastrectomy is cancer recurrence surveillance. This is a crucial aspect of follow-up for most cancers, and for some, such as colorectal and breast cancers, there is firm evidence of survival benefit from randomized controlled trials, supporting this practice [9-11].

The design of optimal follow-up programs after gastrectomy for gastric cancer is a complex task, especially balancing the potential benefits and drawbacks of rigorous recurrence surveillance in the context of a total lack of randomized trials addressing this issue with specific regard to gastric cancer. The pivotal question is whether a potential survival benefit of rigorous surveillance outweighs the monetary costs and possible psychological burden of recurrent anxiety caused by frequent surveillance investigations.

\section{Follow-up components and objectives}

Follow-up after surgery for gastric cancer can be categorized by four main objectives: management of side effects after surgery, cancer recurrence surveillance, psychological 
support, and data collection for treatment evaluation and research.

\section{Management of complications and postgastrectomy syndrome}

All types of gastrectomy for gastric cancer have short-term and long-term effects on gastrointestinal and metabolic function. Some of the short-term problems that patients experience after gastrectomy are related to complications of surgery such as leaks from anastomoses or the duodenal stump or a number of other complications (e.g., ones of pulmonary or cardiovascular origin). However, even in a perfectly uneventful postoperative course, patients experience a number of side effects.

The commonest side effects, often referred to as postgastrectomy syndrome, are related to eating and gastrointestinal tract function and affect virtually all patients to some extent in the first few months after surgery [12, 13]. These side effects include early postprandial satiety, loss of appetite, alteration of taste, nausea/vomiting, and diarrhea. In addition to these expected symptoms, which usually become less apparent with time, there are a number of more specific postgastrectomy symptom complexes, such as dumping syndrome and afferent and efferent loop syndromes, the frequency of which depend on the extent of gastric resection and the type of reconstruction [14].

Important long-term complications following gastrectomy are risks of anemia, caused by deficiencies of iron or vitamin $\mathrm{B}_{12}$, and osteoporosis due to malabsorption of vitamin $\mathrm{D}$ and calcium. Thus, most surveillance programs include monitoring and supplementation of iron, vitamin $\mathrm{B}_{12}$, either orally or parenterally [15], and vitamin $\mathrm{D}$ as well as calcium [16].

Most patients experience weight loss after gastrectomy, which is most pronounced in the early phase and subsequently usually stabilizes within the first 2 years after surgery [17]. One of the reasons for the weight loss is probably the discomfort related to eating described above, but it is also to some extent explained by malabsorption [8, 17-19].

\section{Recurrence surveillance}

The surveillance for recurrence of gastric cancer after curative-intent gastrectomy aims at the detection of local recurrence, either in the surgical resection line or in the regional lymph nodes, as well as the detection of distant metastases. There are a number of different ways that recurrence surveillance programs can be designed with different investigational modalities such as cross-sectional imaging with computerized tomography (CT), with or without positron emission tomography, magnetic resonance imaging, ultrasonography, endoscopy, or tumor markers (TM) in blood samples. However, the main line of division is between surveillance programs that actively seek asymptomatic recurrent disease with regular examination with combinations of imaging, endoscopy, and tumor markers and those follow-up programs that offer clinical assessment only at office visits, with targeted investigation only at the occurrence of symptoms or other reasons to suspect recurrence [8].

\section{Psychological support}

A crucial aspect of follow-up after gastric cancer surgery is to provide psychological support and reassurance to the patient and the surrounding family. This is a complex task given the severity of the disease, with a very high recurrence risk and the extremely poor prognosis in the event of recurrence [20-22], with palliative therapy being the only option in the vast majority of patients in whom recurrence is diagnosed. An important question to address in this context is which of the two main surveillance options, regular scheduled investigation aiming at detection of a presymptomatic phase of cancer recurrence, or symptomdriven investigation only, is most beneficial for patients from a specific psychological and broader quality-of-life perspective.

\section{Data collection for treatment evaluation and research}

The systematic gathering and evaluation of data on patients with gastric cancer is of obvious and major importance. Structured follow-up programs after treatment of gastric cancer, not only in the context of prospective clinical trials but also in the daily clinical practice at every hospital and involving every patient in whom gastric cancer has been diagnosed, are important to meet this objective. In many Western countries, such as the UK, Sweden, Denmark, Germany, and the Netherlands, there are national registries or mandatory national audits, with registration of at least all patients undergoing surgery, but in some countries also including nonsurgically treated patients with gastric cancer $[23,24]$.

\section{Oncological recurrence surveillance in different Western countries}

In a recently published description of clinical pathways for gastric and esophageal adenocarcinoma in ten European countries, it was clearly shown that the pathways used for oncological recurrence surveillance differed immensely, even between these otherwise quite similar western and 
central European countries [7]. Some countries included in the survey such as Denmark, the Netherlands, Ireland, Poland, Sweden, and the UK based their oncological surveillance mainly on clinical assessment at regular office visits, without scheduled cross-sectional imaging or analysis of tumor markers, performing these or other sophisticated investigations only in the event of clinical suspicion of recurrence. Other countries, including France, Germany, Italy, and Spain, had more elaborate programs with actual surveillance for nonsymptomatic recurrence, including scheduled regular cross-sectional imaging with CT and the examination of tumor markers in blood samples. In Poland the clinical evaluations at office visits were supplemented with ultrasonography, and in some of these countries endoscopy was also used for surveillance of local recurrence or new primary tumors in patients with a remnant stomach [7].

Likewise, the practice of recurrence surveillance after gastrectomy for gastric cancer is likely to differ considerably in other Western countries and regions (e.g., in North America, Australia, and New Zealand). However, to my knowledge there are no publications available documenting the postgastrectomy practices in these countries and regions.

\section{Western guidelines and consensus documents}

There are a number of guidelines and consensus documents issued by national and international professional organizations addressing the issue of postgastrectomy follow-up for gastric cancer patients. In some contrast to the differences discussed earlier regarding follow-up practices in different Western countries, Western guidelines from health-profession organizations are quite unanimous in advocating follow-up with symptom-driven recurrence investigations only. These guidelines include the joint ones from the European Society for Medical Oncology, the European Society of Surgical Oncology, and the European Society of Radiotherapy and Oncology from 2013 [25], the joint ones from the Association of Upper Gastrointestinal Surgeons of Great Britain and Ireland, the British Association of Gastroenterology, and the British Association of Surgical Oncology from 2011 [26], and the guidelines from the US National Comprehensive Cancer Network from 2013 [27] In a consensus document, based on the Charter Scaligero Consensus Conference in Verona in 2013, 48 gastric cancer experts from around the world concluded that follow-up after gastrectomy for cancer should be tailored to the stage of the disease, mainly based on crosssectional imaging, and should be discontinued after 5 years [28]. It is notable that this is the only published major consensus guideline, with a predominant influence of
Western experts, advocating regular cross-sectional imaging.

\section{Is there evidence of an oncological benefit of postgastrectomy surveillance?}

For several other cancers, among them notably colorectal and breast cancer, there are a number of randomized clinical trials that clearly show that intensive surveillance for asymptomatic recurrence increases overall survival compared with symptom-driven recurrence investigation only [9-11]. Characteristic for these cancers, however, and in some contrast to the situation regarding gastric cancer, there is a proven strong survival benefit from intense treatment of recurrent distant metastatic disease, including the quite extensive use of therapy guided by molecular profiling and the proven benefit of liver and lung resections for the removal of metastases [9]. Several series have been published reporting long-term survival in selected patients after resection of metachronous gastric cancer liver metastases. However, these series represent highly selected patients, and there are no data from randomized trials. For gastric cancer, there is clear evidence from randomized clinical trials showing a survival benefit of palliative chemotherapy compared with best supportive care only [29-31], although these effects are modest compared with those for the above-mentioned cancer forms. Hence, given that there is a survival benefit from palliative chemotherapy, there is a reasonable rationale for active surveillance for recurrence assuming that early detection may facilitate chemotherapy as a higher proportion of patients are likely to have a high performance status and be able to tolerate treatment, thus possibly enhancing treatment results. On the other hand, there is likewise a risk that more patients may be treated with more side effects and poorer quality of life, without a significant advantage in terms of increased survival. Let us scrutinize the available evidence.

Unfortunately, there are no published or ongoing randomized trials comparing intensive surveillance for nonsymptomatic recurrence with symptom-driven follow-up for gastric cancer. Thus, all the available evidence addressing this important clinical question is observational in nature. See Table 1 for an overview of studies addressing survival benefit of recurrence surveillance.

In 2012 Cardoso et al. [22] published a systematic review summarizing the studies available at that time. All five studies selected to relevantly address the issue were retrospective observational studies, and the authors' conclusion was that there was no evidence to suggest that surveillance after gastrectomy for gastric cancer had any survival benefit. Three of the studies [32-34] simply compared patients with symptomatic recurrences with 
Table 1 Observational studies addressing gastric cancer recurrence surveillance after gastrectomy

\begin{tabular}{|c|c|c|c|c|}
\hline Authors & Publication year & Variables compared & Main outcomes & Results \\
\hline Bohner et al. [33] & 2000 & Symptomatic vs asymptomatic recurrence & PRS & $\begin{array}{l}\text { Longer PRS in asymptomatic } \\
\text { group }\end{array}$ \\
\hline Kodera et al. [34] & 2003 & Symptomatic vs asymptomatic recurrence & PRS, OS & $\begin{array}{l}\text { Longer PRS in asymptomatic } \\
\text { group. No difference in OS }\end{array}$ \\
\hline Bennett et al. [32] & 2005 & Symptomatic vs asymptomatic recurrence & PRS & $\begin{array}{l}\text { Longer PRS in asymptomatic } \\
\text { group }\end{array}$ \\
\hline Tan and So [35] & 2007 & Intensive vs less intensive surveillance & Time to recurrence & $\begin{array}{l}\text { Shorter time to recurrence for } \\
\text { intensive surveillance group, no } \\
\text { difference in OS }\end{array}$ \\
\hline Eom et al. [36] & 2011 & $\begin{array}{l}\text { Recurrence detected by surveillance vs by } \\
\text { symptoms }\end{array}$ & OS & No difference \\
\hline Bilici et al. [37] & 2013 & Symptomatic vs asymptomatic recurrence & DFS, PRS, OS & $\begin{array}{l}\text { Longer DFS, PRS, and OS in } \\
\text { asymptomatic group }\end{array}$ \\
\hline Lee et al. [38] & 2014 & Symptomatic vs asymptomatic recurrence & DFS, PRS, OS & $\begin{array}{l}\text { Longer DFS, PRS, and OS in } \\
\text { asymptomatic group }\end{array}$ \\
\hline Peixoto et al. [39] & 2014 & Intensive vs symptom-driven surveillance & OS & No difference \\
\hline Park et al. [40] & 2016 & Intensive vs less intensive surveillance & OS & No difference \\
\hline
\end{tabular}

$D F S$ disease-free survival, $O S$ overall survival, $P R S$ postrecurrence survival

those with asymptomatic recurrences. They all showed significantly increased postrecurrence survival in patients with asymptomatically detected recurrences, a finding which may very well be entirely explained by lead-time bias. The only one of these three studies that reported overall survival did not observe any difference between symptomatically and asymptomatically detected recurrences [34]. The study by Tan and So [35] compared an intensive follow-up regimen that included twice annual clinical examination, CT, and tumor marker assessment with a regimen with maximal once annual investigation. They found that the intensive surveillance significantly shortened the time to detection of recurrence from a mean of 19.2 months in the low-intensity surveillance group to 11.5 months in the intensive surveillance group $(P=0.02)$, while not significantly affecting overall survival after surgery.

In recent years a few more observational studies addressing the issue of the oncological benefit of intensive surveillance have been published [36-40], Bilici et al. [37] published a retrospective series in 2013, where they, like most previous authors, compared symptomatic recurrences with asymptomatic recurrences and showed significantly longer overall survival among patients with asymptomatic recurrence, in addition to the expected longer postrecurrence survival. There was a slightly longer disease-free survival, reflecting the time to detection of recurrence, in the asymptomatic group. Bilici et al. suggest that these findings may be explained by symptomatic recurrence perhaps being a marker of biological aggressiveness of the cancer. Likewise, Lee et al. [41] found that both postrecurrence survival and overall survival were longer in patients with asymptomatic recurrences, whereas the time to recurrence did not differ, indicating that the increased survival in the asymptomatic group may indeed be due to selection of patients with less aggressive disease rather than to an intervention benefit of surveillance [41].

Recent studies addressing surveillance regimens of different intensity have failed to show any difference in overall survival between these $[39,40]$. In a Canadian cohort study based on prospectively collected data, Peixoto et al. [39] studied patients operated on for gastroesophageal cancer with curative intent and followed up with regimens of different diagnostic intensity. They concluded that after multivariably adjusted analyses, there was no difference in overall survival in a comparison of symptom-driven follow-up with more vigorous surveillance that included regular imaging. Lastly, Park et al. [40], in a study from Korea, compared surveillance programs with CT examinations of different frequency after gastrectomy for gastric cancer, ranging from $\mathrm{CT}$ every 3 months to every 6-12 months, but did observe any difference in overall survival between these groups.

The role of endoscopy in surveillance for cancer recurrence after R0 gastrectomy is very limited [8, 38, 43]. On the other hand, endoscopy does have a significant role in searching for second primary gastric cancers after nontotal gastrectomy [42-44]. Patients who undergo resection for gastric cancer have a significantly increased risk of new primary gastric cancers, and the prognosis in these patients is excellent if detection is early, but poor if a second primary tumor is detected at a later stage (T2 or higher) [44-46]. 


\section{Psychological aspects}

There are no published studies regarding the impact of gastric cancer recurrence surveillance with regard to its psychological effects or effects on health-related quality of life. There is, however, a large body of literature concerning the psychological impact of recurrence surveillance in other cancer forms, especially breast, prostate, and colorectal cancer [47-49]. It is evident from these studies that many patients experience severe anxiety related to testing for recurrence or disease progression.

An important difference between gastric cancer and breast, prostate, and colorectal cancers is that the prognosis, if a recurrence is diagnosed, is relatively good compared with the generally very short life expectancy of patients with recurrent gastric cancer. Adult aggressive lymphoma is a malignant disease with a high degree of prognostic resemblance to gastric cancer. Thompson et al. [50] reported on the psychological impact of recurrence surveillance CT scans after curative-intent treatment of patients with this disease. Using mixed qualitative interview and quantitative techniques, they observed that patients experienced significant anxiety related to the surveillance CT scans, and they concluded that "it is possible that the harm of routine surveillance scans for survivors of aggressive lymphoma may outweigh the value, given the lack of randomized data on the effectiveness of the current practice standards, falsepositive findings, high cost, radiation exposure, and negative emotional impact on patients."

\section{Conclusions}

Follow-up after gastrectomy for gastric cancer has several purposes, including management of side effects after surgery, oncological recurrence surveillance, psychological support, and data collection for research. Despite the fact that guidelines from Western health professional organizations are quite unanimous in recommending symptomdriven recurrence surveillance only, practice in Western countries differs, and often includes intensive surveillance with CT and analysis of tumor markers. There are no data available from randomized controlled trials addressing how recurrence surveillance after gastrectomy for gastric cancer should best be performed. However, the available observational evidence does not support routine surveillance for asymptomatic cancer recurrence. In addition, there is some evidence from other cancers indicating that intensive routine surveillance may have a negative emotional impact on patients. In conclusion, there is a strong need for randomized clinical trials addressing postgastrectomy surveillance intensity with regard to survival, psychological impact, and health-related quality of life.

\section{Compliance with ethical standards}

Conflict of interest The author declares that he has no conflict of interest.

Open Access This article is distributed under the terms of the Creative Commons Attribution 4.0 International License (http://crea tivecommons.org/licenses/by/4.0/), which permits unrestricted use, distribution, and reproduction in any medium, provided you give appropriate credit to the original author(s) and the source, provide a link to the Creative Commons license, and indicate if changes were made.

\section{References}

1. Bonenkamp JJ, Hermans J, Sasako M, van de Velde CJ, Welvaart $\mathrm{K}$, Songun I, et al. Extended lymph-node dissection for gastric cancer. N Engl J Med. 1999;340:908-14.

2. Macdonald JS, Smalley SR, Benedetti J, Hundahl SA, Estes NC, Stemmermann GN, et al. Chemoradiotherapy after surgery compared with surgery alone for adenocarcinoma of the stomach or gastroesophageal junction. N Engl J Med. 2001;345:725-30.

3. Bang YJ, Kim YW, Yang HK, Chung HC, Park YK, Lee KH, et al. Adjuvant capecitabine and oxaliplatin for gastric cancer after D2 gastrectomy (CLASSIC): a phase 3 open-label, randomised controlled trial. Lancet. 2012;379:315-21.

4. Cunningham D, Allum WH, Stenning SP, Thompson JN, Van de Velde CJ, Nicolson M, et al. Perioperative chemotherapy versus surgery alone for resectable gastroesophageal cancer. N Engl J Med. 2006;355:11-20.

5. Sakuramoto S, Sasako M, Yamaguchi T, Kinoshita T, Fujii M, Nashimoto A, et al. Adjuvant chemotherapy for gastric cancer with S-1, an oral fluoropyrimidine. $\mathrm{N}$ Engl $\mathrm{J}$ Med. 2007;357:1810-20.

6. Wu CW, Hsiung CA, Lo SS, Hsieh MC, Chen JH, Li AF, et al. Nodal dissection for patients with gastric cancer: a randomised controlled trial. Lancet Oncol. 2006;7:309-15.

7. Messager M, de Steur W, Boelens PG, Jensen LS, Mariette C, Reynolds JV, et al. Description and analysis of clinical pathways for oesophago-gastric adenocarcinoma, in 10 European countries (the EURECCA upper gastro intestinal group-European Registration of Cancer Care). Eur J Surg Oncol. 2016;42(9):1432-47.

8. D’Ugo D, Biondi A, Tufo A, Persiani R. Follow-up: the evidence. Dig Surg. 2013;30:159-68.

9. Pita-Fernandez S, Alhayek-Ai M, Gonzalez-Martin C, LopezCalvino B, Seoane-Pillado T, Pertega-Diaz S. Intensive follow-up strategies improve outcomes in nonmetastatic colorectal cancer patients after curative surgery: a systematic review and metaanalysis. Ann Oncol. 2015;26:644-56.

10. Renehan AG, Egger M, Saunders MP, O'Dwyer ST. Impact on survival of intensive follow up after curative resection for colorectal cancer: systematic review and meta-analysis of randomised trials. BMJ. 2002;324:813.

11. Smith TJ, Davidson NE, Schapira DV, Grunfeld E, Muss HB, Vogel VG 3rd, et al. American Society of Clinical Oncology 1998 update of recommended breast cancer surveillance guidelines. J Clin Oncol. 1999;17:1080-2.

12. Jentschura D, Winkler M, Strohmeier N, Rumstadt B, Hagmuller E. Quality-of-life after curative surgery for gastric cancer: a comparison between total gastrectomy and subtotal gastric resection. Hepatogastroenterology. 1997;44:1137-42.

13. Kong H, Kwon OK, Yu W. Changes of quality of life after gastric cancer surgery. J Gastric Cancer. 2012;12:194-200. 
14. Eagon JC, Miedema BW, Kelly KA. Postgastrectomy syndromes. Surg Clin N Am. 1992;72:445-65.

15. Kim HI, Hyung WJ, Song KJ, Choi SH, Kim CB, Noh SH. Oral vitamin B12 replacement: an effective treatment for vitamin B12 deficiency after total gastrectomy in gastric cancer patients. Ann Surg Oncol. 2011;18:3711-7.

16. Tovey FI, Hobsley M. Post-gastrectomy patients need to be followed up for 20-30 years. World J Gastroenterol. 2000;6:45-8.

17. Davis JL, Selby LV, Chou JF, Schattner M, Ilson DH, Capanu M, et al. Patterns and predictors of weight loss after gastrectomy for cancer. Ann Surg Oncol. 2016;23:1639-45.

18. Tovey FI, Hall ML, Ell PJ, Hobsley M. Postgastrectomy osteoporosis. Br J Surg. 1991;78:1335-7.

19. Bae JM, Park JW, Yang HK, Kim JP. Nutritional status of gastric cancer patients after total gastrectomy. World J Surg. 1998;22:254-60; discussion 260-1.

20. Shiraishi N, Inomata M, Osawa N, Yasuda K, Adachi Y, Kitano $\mathrm{S}$. Early and late recurrence after gastrectomy for gastric carcinoma. Univariate and multivariate analyses. Cancer. 2000;89:255-61.

21. Katai H, Maruyama K, Sasako M, Sano T, Okajima K, Kinoshita $\mathrm{T}$, et al. Mode of recurrence after gastric cancer surgery. Dig Surg. 1994;11:99.

22. Cardoso R, Coburn NG, Seevaratnam R, Mahar A, Helyer L, Law $\mathrm{C}$, et al. A systematic review of patient surveillance after curative gastrectomy for gastric cancer: a brief review. Gastric Cancer. 2012;15:S164-7.

23. Royal College of Surgeons of England. National oesophagogastric cancer audit-2012, annual report. 2012.

24. Regionala Cancercentrum i Samverkan (RCC). Nationellt kvalitetsregister matstrups-och magsäckscancer (NREV). 2016.

25. Waddell T, Verheij M, Allum W, Cunningham D, Cervantes A, Arnold D. Gastric cancer: ESMO-ESSO-ESTRO clinical practice guidelines for diagnosis, treatment and follow-up. Ann Oncol. 2013;24(Suppl 6):vi57-63.

26. Allum WH, Blazeby JM, Griffin SM, Cunningham D, Jankowski JA, Wong R. Guidelines for the management of oesophageal and gastric cancer. Gut. 2011;60:1449-72.

27. National Comprehensive Cancer Network. Clinical practice guidelines in oncology (NCCN Guidelines)-gastric cancer. Version 3.2016. 2016.

28. Baiocchi GL, D’Ugo D, Coit D, Hardwick R, Kassab P, Nashimoto A, et al. Follow-up after gastrectomy for cancer: the Charter Scaligero Consensus Conference. Gastric Cancer. 2016;19:15-20.

29. Murad AM, Santiago FF, Petroianu A, Rocha PR, Rodrigues MA, Rausch M. Modified therapy with 5-fluorouracil, doxorubicin, and methotrexate in advanced gastric cancer. Cancer. 1993;72:37-41.

30. Glimelius B, Ekstrom K, Hoffman K, Graf W, Sjoden PO, Haglund U, et al. Randomized comparison between chemotherapy plus best supportive care with best supportive care in advanced gastric cancer. Ann Oncol. 1997;8:163-8.

31. Pyrhonen S, Kuitunen T, Nyandoto P, Kouri M. Randomised comparison of fluorouracil, epidoxorubicin and methotrexate (FEMTX) plus supportive care with supportive care alone in patients with non-resectable gastric cancer. $\mathrm{Br} \mathrm{J}$ Cancer. 1995;71:587-91.

32. Bennett JJ, Gonen M, D'Angelica M, Jaques DP, Brennan MF, Coit DG. Is detection of asymptomatic recurrence after curative resection associated with improved survival in patients with gastric cancer? J Am Coll Surg. 2005;201:503-10.

33. Bohner H, Zimmer T, Hopfenmuller W, Berger G, Buhr HJ. Detection and prognosis of recurrent gastric cancer-is routine follow-up after gastrectomy worthwhile? Hepatogastroenterology. 2000;47:1489-94.

34. Kodera Y, Ito S, Yamamura Y, Mochizuki Y, Fujiwara M, Hibi $\mathrm{K}$, et al. Follow-up surveillance for recurrence after curative gastric cancer surgery lacks survival benefit. Ann Surg Oncol. 2003;10:898-902.

35. Tan IT, So BY. Value of intensive follow-up of patients after curative surgery for gastric carcinoma. J Surg Oncol. 2007;96:503-6.

36. Eom BW, Ryu KW, Lee JH, Choi IJ, Kook MC, Cho SJ, et al. Oncologic effectiveness of regular follow-up to detect recurrence after curative resection of gastric cancer. Ann Surg Oncol. 2011;18:358-64.

37. Bilici A, Salman T, Oven Ustaalioglu BB, Unek T, Seker M, Aliustaoglu $\mathrm{M}$, et al. The prognostic value of detecting symptomatic or asymptomatic recurrence in patients with gastric cancer after a curative gastrectomy. J Surg Res. 2013;180:e1-9.

38. Lee SY, Lee JH, Hwang NC, Kim YH, Rhee PL, Kim JJ, et al. The role of follow-up endoscopy after total gastrectomy for gastric cancer. Eur J Surg Oncol. 2005;31:265-9.

39. Peixoto RD, Lim HJ, Kim H, Abdullah A, Cheung WY. Patterns of surveillance following curative intent therapy for gastroesophageal cancer. J Gastrointest Cancer. 2014;45:325-33.

40. Park CH, Park JC, Chung H, Shin SK, Lee SK, Cheong JH, et al. Impact of the surveillance interval on the survival of patients who undergo curative surgery for gastric cancer. Ann Surg Oncol. 2016;23:539-45.

41. Lee JH, Lim JK, Kim MG, Kwon SJ. The influence of postoperative surveillance on the prognosis after curative surgery for gastric cancer. Hepatogastroenterology. 2014;61:2123-32.

42. Fujita T, Gotohda N, Takahashi S, Nakagohri T, Konishi M, Kinoshita T. Relationship between the histological type of initial lesions and the risk for the development of remnant gastric cancers after gastrectomy for synchronous multiple gastric cancers. World J Surg. 2010;34:296-302.

43. Ohashi M, Katai H, Fukagawa T, Gotoda T, Sano T, Sasako M. Cancer of the gastric stump following distal gastrectomy for cancer. Br J Surg. 2007;94:92-5.

44. Greene FL. Management of gastric remnant carcinoma based on the results of a 15-year endoscopic screening program. Ann Surg. 1996;223:701-6; discussion 706-8.

45. Kikuchi S, Sato M, Katada N, Sakuramoto S, Shimao H, Kakita A, et al. Efficacy of endoscopic surveillance of the upper gastrointestinal tract following distal gastrectomy for early gastric cancer. Hepatogastroenterology. 2003;50:1704-7.

46. Kato M, Nishida T, Yamamoto $K$, Hayashi S, Kitamura S, Yabuta $\mathrm{T}$, et al. Scheduled endoscopic surveillance controls secondary cancer after curative endoscopic resection for early gastric cancer: a multicentre retrospective cohort study by Osaka University ESD Study Group. Gut. 2013;62:1425-32.

47. Deimling GT, Bowman KF, Sterns S, Wagner LJ, Kahana B. Cancer-related health worries and psychological distress among older adult, long-term cancer survivors. Psychooncology. 2006;15:306-20.

48. Klotz L. Active surveillance, quality of life, and cancer-related anxiety. Eur Urol. 2013;64:37-9.

49. Kash KM, Holland JC, Halper MS, Miller DG. Psychological distress and surveillance behaviors of women with a family history of breast cancer. J Natl Cancer Inst. 1992;84:24-30.

50. Thompson CA, Charlson ME, Schenkein E, Wells MT, Furman RR, Elstrom R, et al. Surveillance CT scans are a source of anxiety and fear of recurrence in long-term lymphoma survivors. Ann Oncol. 2010;21:2262-6. 